\title{
The role of stage-specific oligonucleotide primers in providing effective laboratory support for the molecular diagnosis of reactivated Toxoplasma gondii encephalitis in patients with AIDS
}

\author{
CARLO CONTINI, ROSARIO CULTRERA, SILVA SERACENI, DANIELA SEGALA, \\ ROBERTO ROMANI*, ENRICO FAINARDI + , PAOLA CINQUE $\dagger$, ADRIANO LAZZARIN $\dagger$ and \\ SALVATORE DELIA*
}

\begin{abstract}
Section of Infectious Diseases, Department of Clinical \& Experimental Medicine, University of Ferrara, via Fossato di Mortara 23, 44100 Ferrara, *Department of Infectious and Tropical Diseases, "La Sapienza" University, Policlinico Umberto 1², via Regina Elena 331, 00161 Rome, †Division of Infectious Diseases, San Raffaele Hospital, Via Stamira d'Ancona, 20, 20127 Milano and \$Section of Neurologic Clinic, University of Ferrara, Arcispedale S. Anna, C.so Giovecca 203, Ferrara, Italy
\end{abstract}

\begin{abstract}
The switch from bradyzoites to tachyzoites is the fundamental pathogenic event that leads to Toxoplasma gondii encephalitis (TE) in patients with AIDS. Distinction between these stages is difficult, particularly when specific treatment has been started. A new approach consisting of a nested PCR (n-PCR) assay was performed on cerebrospinal fluid (CSF) specimens collected from AIDS patients with TE before or after antiparasitic therapy was initiated, to assess the efficacy of primer sets which amplify target sequences expressed on bradyzoites (SAG4 and MAG1), tachyzoites (SAG1) or both stages (B1) of $T$. gondii. CSF specimens were obtained from 46 patients with AIDS, of whom 27 had TE (16 first episode, 11 relapse) and 19 had other AIDS-related brain lesions (AIDS-OBL) in the absence of TE. CSF specimens from 26 HIV-negative and immunocompetent patients were also checked. All samples were tested with different primer pairs targeting the B1, SAG-1, SAG-4 and MAG-1 genes. With B1, 75\% of patients with first episodes of TE were positive, compared with $36.3 \%$ of those with relapse of TE and 5.2\% of those with AIDS-OLB. The SAG1 gene yielded positive values in $28.7 \%$ and $45.4 \%$ of patients with first episodes of TE or relapse of TE, respectively, and in none of the controls. With the SAG4 and MAG1 genes, $72.7 \%$ of patients with relapse of TE were detected, compared with $25 \%$ of patients with first episodes of TE and 5.2\% with AIDS-OLB. None of the HIV-negative subjects showed positive PCR reactions. These results demonstrate that specific primers for the genes SAG4, MAG1 and SAG1 may be useful in AIDS patients with relapse of TE, in whom the use of PCR targeting the B1 gene may fail to detect DNA, especially when prophylaxis or treatment has been started.
\end{abstract}

\section{Introduction}

Toxoplasma gondii encephalitis (TE) in patients with AIDS results from the stage conversion from the encysted bradyzoites located in tissue cysts to tachyzoites. Recognition of individual stages of $T$. gondii is

Received 24 Jan. 2002; revised version received 28 May 2002; accepted 6 June 2002.

Corresponding author: Professor C. Contini (e-mail: cnc@dns.unife.it). difficult, but could be crucial for correctly diagnosing TE. However, the cyst antigens are predominantly located in brain and muscle and the serological response may be inefficient, or there may be tolerance toward these components [1].

Bradyzoites can be differentiated from tachyzoites by their slower replication rate, morphological criteria and expression of stage-specific surface antigens that are induced during the interconversion. Some of these components have been characterised previously by monoclonal antibodies, which have in part facilitated 
investigations of the tachyzoite/bradyzoite differentiation $[1-3]$.

Most diagnostic studies have been concerned with the development of PCR-based techniques to detect $T$. gondii DNA in different clinical specimens including blood, brain biopsy and cerebrospinal fluid (CSF). Although most of these techniques make use of the most conserved gene sequences among different strains of $T$. gondii $[4,5]$, acute and latent phases of infection cannot be distinguished easily. Additional evidence also suggests that most current anti- $T$. gondii therapy acts against the tachyzoite stage and often clears $T$. gondii DNA from the CSF a few days after the start of treatment or when lumbar puncture is delayed. This may account for the failure of PCR which targets the B1 gene [6-11]. Recently, cloning of stage-specifically expressed genes, such as SAG1, located in the tachyzoites, or BAG1, SAG4 and MAG1, located in the bradyzoites, has enabled further analysis of regulatory mechanisms that are involved in the stage interconversion and provided insights into the pathogenesis of toxoplasmosis [3, 12-18].

In this study, the diagnostic efficiency of a nested PCR with different primer sets directed against the B1, SAG1, SAG4 and MAG1 genes was assessed, to compare and determine which sequences were most effective in detecting $T$. gondii DNA in CSF samples from AIDS patients undergoing antiparasitic treatment and with first episode of TE or relapse.

\section{Materials and methods}

\section{Patients and clinical specimens}

CSF specimens collected from $72 \mathrm{HIV}$-infected patients with neurological complications between Jan. 1995 and Jan. 2000 were analysed retrospectively. All patients were hospitalised in an Infectious Disease Department in one of three Italian University Hospitals: Ferrara (Section of Infectious Diseases, Arcispedale S. Anna); Rome (Policlinico Umberto $1^{\circ}$, University "La Sapienza"); and Milan (Clinic of Infectious Diseases, S. Raffaele Hospital). Patients were divided into three groups.

Group 1 consisted of 27 patients (mean age, 28 years; 21 men; mean $\mathrm{CD}^{+}$lymphocyte count, $47 \mathrm{SD} 2.8 \times$ $10^{6} / \mathrm{L}$ ), with confirmed or presumed TE. Diagnosis of TE was based upon the criteria of the Centers for Disease Prevention and Control (CDC) in the presence of signs and symptoms of central nervous system (CNS) dysfunction, typical lesions on computed tomography (CT) or magnetic resonance imaging (MRI) of the brain, and clinical and radiological improvement after treatment for 2-3 weeks with specific anti-toxoplasma drugs (pyrimethamine plus sulphadiazine or clindamycin; pyrimethamine plus azithromycin or atovaquone). Diagnosis was confirmed at autopsy in seven cases. Neuropathological examination of autopsy cases was performed on standard sections obtained from parietal, frontal and temporal lobes, basal ganglia, cerebellum and from any macroscopic lesions. Sections were fixed in formalin $5 \%$, embedded in paraffin and routinely stained with haematoxylin and eosin. The periodic acid-Schiff (PAS) reaction and trichrome light green (Masson stain) were applied when necessary. T. gondii was detected by a polyclonal antibody directed against whole T. gondii parasites (Quartett, Berlin, Germany). Immunohistochemistry was performed by a standard alkaline phosphatase-anti-alkaline phosphatase (APAAP) method. Serum T. gondii-specific immunoglobulin G (IgG) and IgM, detected by indirect immunofluorescence assay or automated quantitative ELISA (Enzygnost toxoplasmosis/IgG-IgM, Behring, Marburg, Germany), were present in all but six cases. No patient had IgM antibodies nor was Toxoplasma-specific seroconversion demonstrated. Furthermore, none of these patients had received highly active antiretroviral therapy (HAART) at the time of sample collection.

TE cases were separated into first episodes (16 patients) and relapses (11 patients). In first episodes, CSF samples were taken before (12 patients) or 816 days after the start of specific anti- $T$. gondii therapy (4 patients) which consisted of a combination of pyrimethamine plus sulphadiazine or clindamycin or azithromycin, co-trimoxazole or atovaquone. In relapses, seven patients were receiving maintenance antitoxoplasma prophylaxis (pyrimethamine plus sulphadiazine, pyrimethamine plus clindamycin or co-trimoxazole, atovaquone) after resolution of an acute episode of TE; two patients were receiving full dose therapy (pyrimethamine plus sulphadiazine) whereas two patients were not receiving anti-TE drugs because of refusal or intolerance when CSF was obtained.

A TE relapse was defined as the occurrence of clinical and neurological symptoms associated with the presence, on neuroimaging, of intracerebral lesions suggestive of toxoplasmic abscess or as the recurrence of acute neurological symptoms only, in the absence of cerebral CT or MRI examination. For TE relapses, mean duration of anti- $T$. gondii treatment at the time of lumbar puncture was 7 days (range, 1-11 days). Patients had baseline and periodic clinical and laboratory evaluations with a detailed examination to detect signs of TE.

Group 2 consisted of 19 patients (mean age, 31 SD 1.1 years; 8 men; mean $\mathrm{CD}^{+}{ }^{+}$lymphocyte count, $51 \mathrm{SD}$ $3.7 \times 10^{6} / \mathrm{L}$ ), with other AIDS-related brain lesions (AIDS-OBL) with or without mass effect. These included HIV encephalitis (four patients), cytomegalovirus (CMV) encephalitis (four patients), progressive multifocal leucoencephalopathy (PML, three patients), aspergillosis (three patients), cryptococcosis (two patients), primary CNS lymphoma (P-CNSL, one patient) 
and vascular disorders (two patients). Cases of HIV encephalitis, CNS aspergillosis and P-CNSL were diagnosed at autopsy; cases of PML, CMV encephalitis and cryptoccocosis were diagnosed by the presence of consistent clinical symptoms and signs and demonstration of JCV-DNA, CMV-DNA or cryptococcal antigen in the CSF, respectively. All but four patients had no anti-toxoplasma antibodies. Two patients with PML received an initial course of anti-TE therapy but showed no improvement. For Groups 1 and 2, CSF was drawn by lumbar puncture, after written informed consent.

Group 3 consisted of 26 HIV-negative and immunocompetent patients, serologically positive or negative for toxoplasma antibodies, who suffered from other inflammatory neurological diseases (OIND) or noninflammatory neurological disorders (NIND) and were attending the Neurologic Clinic of Ferrara; they underwent lumbar puncture for diagnostic evaluation and CSF analysis. CSF was drawn if there was no contraindication and after obtaining informed consent.

\section{Laboratory conditions for PCR}

Precautions were taken to avoid the risk of contamination by exogenous DNA or PCR product carryover [19]. Sample lysis and extraction of nucleic acids, preparation and dispensing of PCR mixture and the addition of the samples to the PCR mixture were performed in three separate rooms in biosafety cabinets dedicated exclusively to these molecular procedures. Thermal cyclers were located in a fourth room. Each room had dedicated laboratory coats or gowns, gloves, foot covers and cleaning supplies. Moreover, all purchased reagents were split into small volumes, dedicated disposable pipettes (Eppendorf, $\mathrm{GmbH}$, Germany) were autoclaved frequently, tips for pipetting the reagents were equipped with sealing filters (Filtertips, Eppendorf) and all areas of biosafety cabinets were UV irradiated and decontaminated with sodium hypochlorite and ethyl alcol $70 \%$ before and after each phase of PCR. The negative controls (PCR mixture without DNA) were included in duplicate at the final stage of dispensing the PCR mixture. Further precautions were taken (frequent change of gloves, quickly spinning tubes before opening them, uncapping and closing tubes carefully to prevent aerosols, capping each tube after the addition of DNA sample) before proceeding to the next sample.

\section{Preparation of specimens and extraction of DNA}

After collection, CSF specimens were separated in two samples. A small sample was used for microbiological culture; the other was stored at $-20^{\circ} \mathrm{C}$ for subsequent DNA amplification, as described previously [20]. Briefly, each sample $(100 \mu \mathrm{l})$ was thawed in an ice bath and added to an equal volume of lysis buffer containing proteinase $\mathrm{K} 200 \mu \mathrm{g} / \mathrm{ml}$, incubated for $1 \mathrm{~h}$ at $56^{\circ} \mathrm{C}$ and then heated at $95^{\circ} \mathrm{C}$ for $10 \mathrm{~min}$ in a water bath and cooled to room temperature. T. gondii DNA was extracted with phenol:chloroform:isoamyl alcohol $(25: 24: 1 \quad \mathrm{v}: \mathrm{v}: \mathrm{v})$, optimising the recovery by use of Phase Lock Gel tube (Eppendorf $\mathrm{GmbH}$ ), followed by precipitation with ethanol, and resuspended in $50 \mu \mathrm{l}$ of TE buffer.

\section{Amplification and detection of T. gondii DNA by nested PCR (n-PCR)}

n-PCR was performed by two steps with different primer pairs which amplify the 35 -fold repetitive DNA region $B 1$ of $T$. gondii, the SAG1 gene codifying for tachyzoite surface antigen P-30, and the SAG4 and MAG1 genes which encode for the bradyzoite $18-\mathrm{kDa}$ surface protein and the $65-\mathrm{kDa}$ antigen of the cystic surface, respectively (Fig. 1). The oligonucleotide primers employed and the correct DNA amplification product sizes in the first and second cycles are shown in Table 1.

All samples were tested for the presence of PCR inhibitors by adding an undiluted and 10-fold diluted samples of pBR322 DNA $10 \mathrm{ng}$ (Promega, Madison, WI, USA) with specific primers PBR1/PBR2 (719 bp). PCR was performed with a PTC-100 thermal cycler (MJ Research, MA, USA) in $50 \mu \mathrm{l}$ of amplification mixture containing $1.5 \mathrm{mM} \mathrm{MgCl} 2,0.2 \mathrm{mM}$ of dNTP (Amersham Pharmacia Biotech AB, Uppsala, Sweden), 10 pmol of each primer for the T. gondii gene and $2 \mathrm{U}$ of Taq DNA polymerase (Promega).

Amplification of the B1 target gene (GenBank AF179871) of $T$. gondii was performed with two sets of primer pairs with some modifications, as described previously [4, 21]. SAG1 gene (GenBank - X14080) was amplified according to previously described methods [16] and SAG4 gene (GenBank - Z69373) amplification was based on primer pairs derived from Ödberg-Ferragut et al. with modified conditions of PCR to increase the stringency [22].

Oligonucleotide primers within the MAG 1 gene (GenBank- U09029), originally sequenced by Parmley et al. [14], were deduced by us [20]. After the second amplification round, MAG1-positive samples showed a 212-bp band. The other expected amplification products for SAG1, SAG4 and B1 gene were 521, 187 and $126 \mathrm{bp}$ (Fig. 2), respectively. PCR products were analysed by agarose gel (agarose-HR 2:1, Ambion, Austin, TX, USA) electrophoresis at different percentages according to the size of amplified products and stained with ethidium bromide.

All PCR reactions were repeated at least twice with two positive (DNA extracted from a virulent RH strain of $T$. gondii grown in monolayers of MRC-5 cells) and two negative (reaction mixtures without DNA) controls for each run. Specimens that yielded a specific positive 
a

\section{B1 (AF179871)}

1

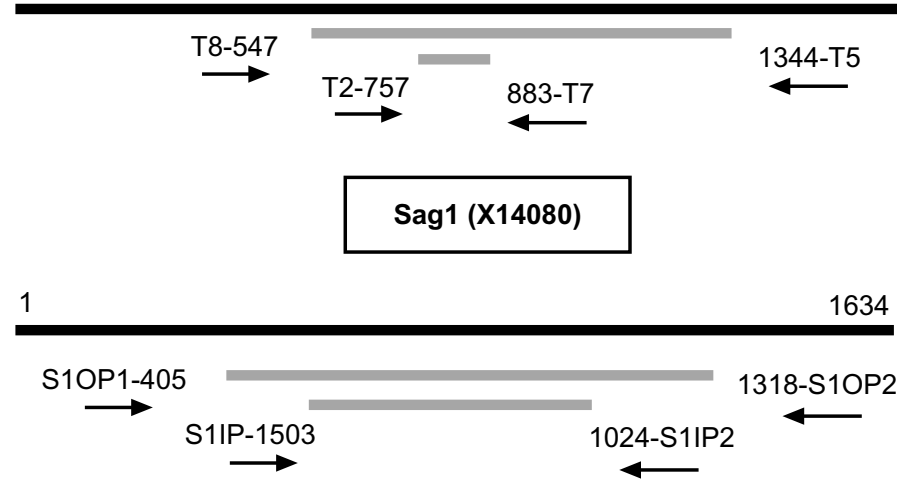

Sag4 (Z69373)

1

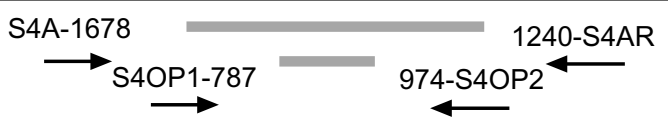

Mag1 (U09029)

1

b

$\begin{array}{lr}\text { Primer pairs } & b p \\ \text { T8/T5 } & 797 \\ \text { T2/T7 } & 126 \\ \text { S1OP1/S1OP2 } & 913 \\ \text { S1IP1/S1IP2 } & 521 \\ \text { S4-A/S4AR } & 562 \\ \text { S4OP1/S4OP2 } & 187 \\ \text { M1OP1/M1OP2 } & 518 \\ \text { M1IP1/M1IP2 } & 212\end{array}$

Fig. 1. (a) Maps of B1, SAG1, SAG4 and MAG1 (GenBank accession nos) genes of T. gondii and schematic representation of PCR amplified products with locations. Arrows indicate directions of primers and numbers show the location of primer in the gene sequence. (b) Combination of corresponding forward and reverse primers employed in n-PCR with length of amplicons of each amplified gene target.

signal with each primer pair in at least two assays were considered positive. All positive CSF samples gave positive results in two different PCR amplifications, confirming the reproducibility of the assay.

\section{Sequencing analysis}

Cycle sequencing (Ampli-Cycle Sequencing Kit, Perkin Elmer, CA, USA) was performed by adding to $2 \mu \mathrm{l}$ of each of the A, T, G and C termination mixtures, $6 \mu \mathrm{l}$ of the reaction mixture containing $18.5 \mu \mathrm{C}\left[a^{35} \mathrm{~S}\right]$-dATP (Redivue $^{\mathrm{TM}}$, Amersham Pharmacia Biotech), $0.5 \mu \mathrm{M}$ of each primer, $5 \mathrm{ng}$ of PCR purified product and $4 \mu \mathrm{l}$ of cycling buffer [23]. Analysis was performed by polyacrylamide gel electrophoresis and confirmed by the ABI PRISM 377 DNA Sequencer.

\section{Sensitivity and specificity of the $n-P C R$ assay}

A suspension containing T. gondii tachyzoites 
$5 \times 10^{5} / \mathrm{ml}$ was centrifuged at $1000 \mathrm{~g}$ at $4^{\circ} \mathrm{C}$ for $15 \mathrm{~min}$; the pellet was resuspended in washing buffer (10 mM Tris- $\mathrm{HCl}, 50 \mathrm{mM} \mathrm{KCl}, 1.5 \mathrm{~mm} \mathrm{MgCl}_{2}$ ) and centrifuged twice as above. To obtain $T$. gondii concentrations of $10^{-1}-10^{5}$, to define the sensitivity of the PCR assay, 10-fold dilutions in PBS were employed. The limit of detection of n-PCR ranged from c. 1 parasite $(3 \mathrm{fg})$ to 100 parasites $(100 \mathrm{fg}) / \mathrm{ml}$. The T. gondii DNA control used ranged from 1 to 10 parasites $/ \mathrm{ml}$.

Specificity of the various oligonucleotides was determined by PCR amplification of DNA extracted from various bacterial species (Staphylococcus aureus, $S$. epidermidis, Streptococcus pneumoniae, Pseudomonas aeruginosa, Serratia marcescens, Escherichia coli, Klebsiella pneumoniae, Mycobacterium spp.), fungi (Aspergillus fumigatus, Candida albicans, C. parapsilosis, Cryptococcus neoformans) and cytomegalovirus (CMV), and from healthy human subjects and by a theoretical alignment with the entire complement of DNA from the GenBank ${ }^{\mathrm{TM}}$ Basic Local Alignment Search Tool (BLAST).

\section{Southern blot assay}

To further define the sensitivity and specificity of nPCR, the amplification assay was combined with Southern blot hybridisation. PCR product fragments of n-PCR were separated on an agarose $1 \%$ gel, denatured in neutral buffer $(0.5 \mathrm{M} \mathrm{NaOH}, 1.5 \mathrm{M} \mathrm{NaCl})$ and transferred to nylon membrane (Nytran N, $0.2 \mu \mathrm{m}$ ) by the TurboBlotter System (Schleicher \& Schuell $\mathrm{GmbH}$, Dassel, Germany) in $20 \times$ SSC transfer buffer. Membranes were placed in hybridisation buffer, prehybridised at $45-50^{\circ} \mathrm{C}$ (according to the probe used) for $60 \mathrm{~min}$, and then hybridised for $2 \mathrm{~h}$ at the same temperature in a Shake'n'Stack hybridisation oven (Hybaid, Ashford) with labelled oligonucleotides internal to amplified sequences under highly stringent conditions (Table 2). These probes were tailed at the 3 '-end with fluorescein-11-dUTP (Fl-dUTP) and employed at a final concentration of $10 \mathrm{ng} / \mathrm{ml}$ [24].

A clinical sample was considered to be $T$. gondii DNApositive if the n-PCR amplicons hybridised with the specific probe in Southern blotting experiment (Fig. 3).

\section{Statistical analysis}

The statistical significance of CSF-PCR results with the various primers employed among specimens from different patient groups was calculated by the analysis of variance (ANOVA) and the Student-Newman-Keuls multiple comparisons test. A difference was considered significant at $\mathrm{p}<0.05$.

A statistical analysis was also performed for the sequence homology. Results of theoretical alignment from the BLAST search were expressed in expectation 


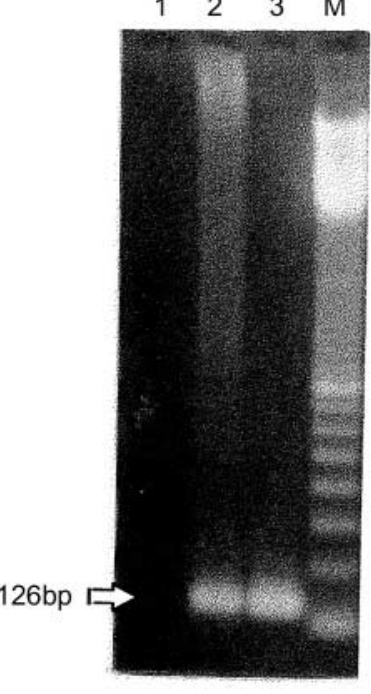

B1

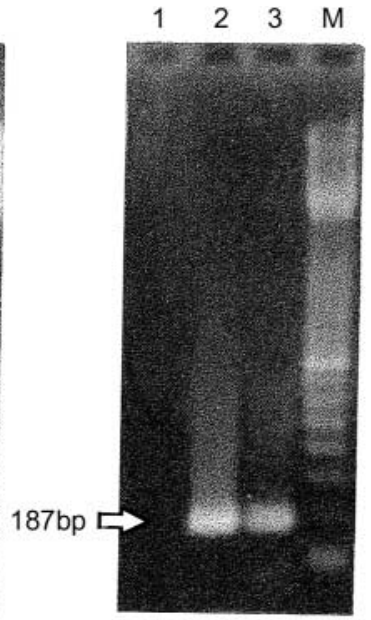

SAG4

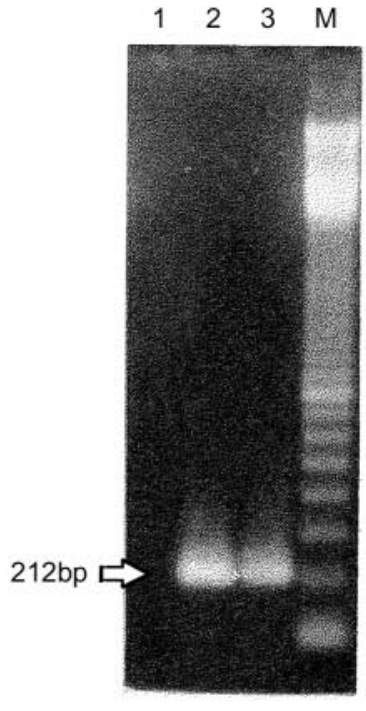

MAG1

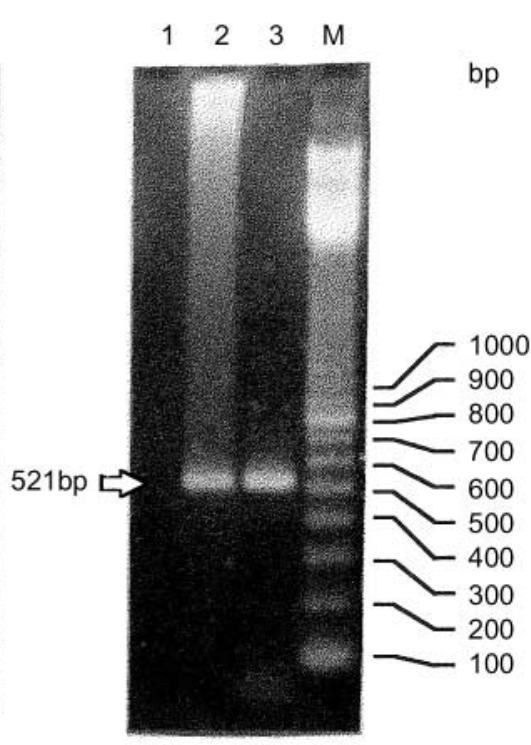

SAG1

Fig. 2. Agarose 1.5\% gel electrophoresis showing amplification fragments of B1, SAG4, MAG1 and SAG1 of $T$. gondii obtained by n-PCR. Lane 1: mixture of PCR amplification wiithout DNA samples; 2, clinical sample; 3, T. gondii DNA positive control; M, molecular size marker (100-bp ladder). Arrows indicate the position of each amplicon.

Table 2. Oligonucleotide probes employed in Southern blot hybridisation

\begin{tabular}{lll}
\hline Gene & $\begin{array}{l}\text { Probe } \\
\text { name }\end{array}$ & $\begin{array}{l}\text { Sense sequence } \\
\left(\text { gene location } 5^{\prime} \rightarrow 3^{\prime}\right)\end{array}$ \\
\hline$B 1$ & B1-T3 & GGC GAC CAA TCT GCG AAT ACA CC (853-831) \\
$S A G 1$ & P30-p1 & TTG TGG TCG GTT GCA TCA AGG GA (780-802) \\
& P30-p2 & ACT ACA ATG ACC CTC GTG TGC (935-955) \\
SAG4 & S4-p1 & GAG ATT ATC ACA CCG GG (835-851) \\
& S4-p2 & GGC GGG ATG TAC TCA AGA GG (905-886) \\
MAG1 & M1-p1 & TGT TCT GCC ACC TGC ACC GGT A (1383-1404) \\
& M1-p2 & AGA CAT CCA CCC GGA TCA GGT T(1467-1488) \\
\hline
\end{tabular}

values (E-value). A closest match for the homology analysis was with an E-value at $<0.01[25,26]$.

\section{Results}

A synopsis of the investigated patients with TE is given in Table 3. Table 4 shows the results obtained by $\mathrm{n}$-PCR in comparing the different gene targets. With $\mathrm{B} 1$ gene n-PCR, a CSF-positive finding was obtained in 12 proven cases with a first episode of TE; CSF samples had been drawn before starting specific antiTE therapy in all of these cases. No DNA amplification was found in the further four patients in whom CSF was taken after the start of therapy.

In TE relapses by contrast, $T$. gondii DNA was detected with B1 gene in n-PCR in 4 of 11 patients: 2 of them were receiving maintenance anti-TE prophylaxis and 2 were untreated. No DNA signal was detected in two patients who were receiving full dose treatment or in four patients who were receiving maintenance therapy. The proportion of n-PCR-positive results was significantly lower than in patients with first episodes of TE ( $\mathrm{p}<0.05$ ). The SAG1 gene n-PCR detected $T$. gondii DNA in three patients with first episodes of TE and five of those with TE relapse ( $p=$ not significant). In patients with TE relapse, both SAG4 and MAG1 n-PCR assays gave a significantly higher yield of $T$. gondii-specific DNA than was found with samples from patients with first episodes of TE $(p<0.01)$. Samples from patients 7, 14 and 17 were either SAG4- or MAG1-positive. All other patients that gave positive results in the SAG4 gene assay were also positive for the MAG1 gene. No differences in either amplification signal or detection rate were observed between patients with relapse who were receiving secondary anti-TE maintenance prophylaxis or who were receiving full dose regimens.

Amplified DNA from n-PCR-positive samples always hybridised with the corresponding gene probe. n-PCRnegative samples also gave negative hybridisation results with the B1, SAG1, SAG4 and MAG1 probes. When the amplification assay was combined with Southern blot hybridisation, the sensitivity decreased to $10 \mathrm{fg} / \mathrm{ml}$ of $T$. gondii DNA that corresponded to $c$. 10 parasites $/ \mathrm{ml}$.

Among AIDS-OBL patients, the B1, SAG4 and MAG1 $\mathrm{n}$-PCR assays gave positive results in one case each (5.2\%). Amplified DNA from these PCR-positive samples did not hybridise with the corresponding gene probe. Moreover, none of the reported T. gondii 

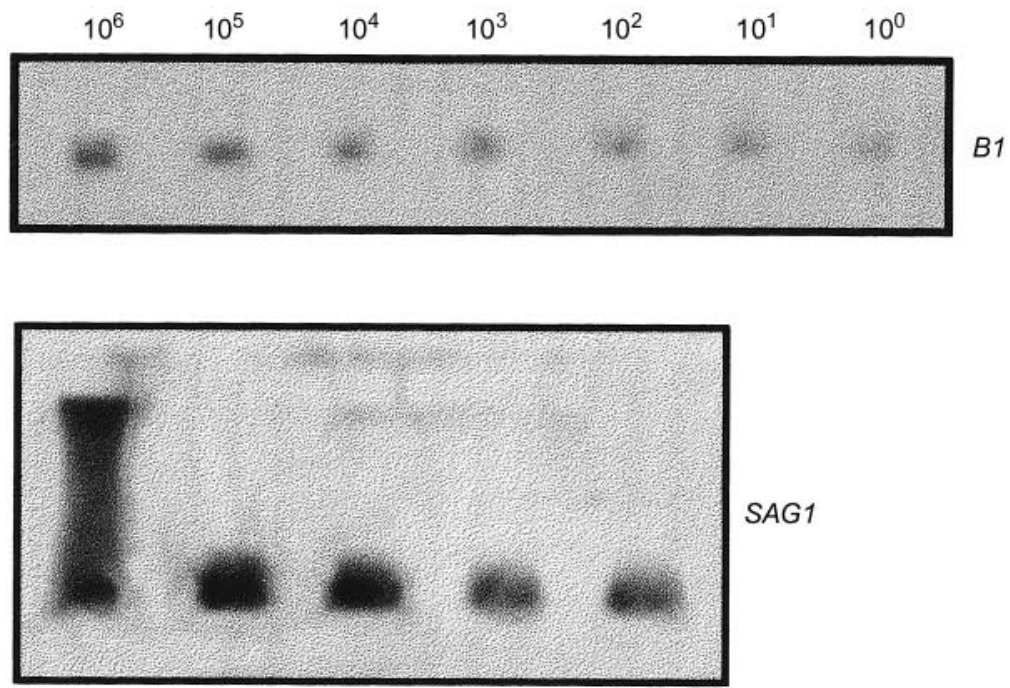

SAG1
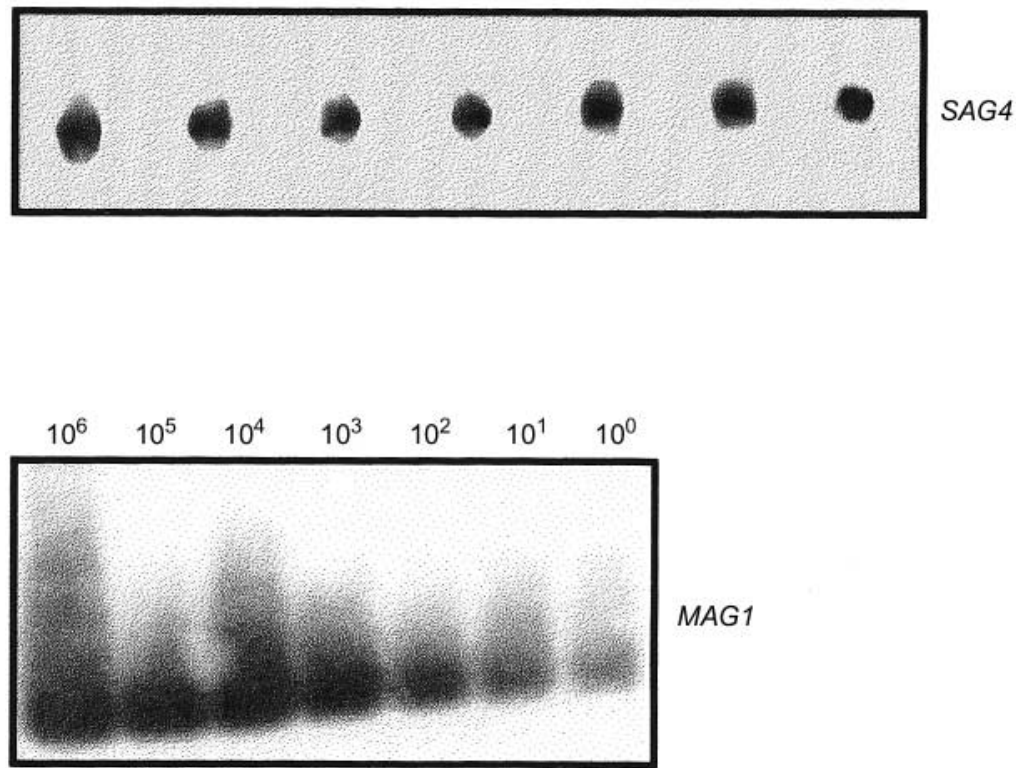

Fig. 3. Agarose 1\% gel electrophoresis of n-PCR amplified products of B1, SAG1, SAG4 and MAG1 T. gondii genes after Southern blot transfer and hybridisation with gene-specific probes. T. gondii DNA target was obtained from different concentrations $\left(10^{6}-\right.$ $10^{0}$ parasites $/ \mathrm{ml}$ ) corresponding to parasite DNA dilutions ( $\left.1 \mathrm{ng}-3 \mathrm{fg}\right)$.

sequences amplified by the primers used in this work aligned with sequences of other human pathogens in the GenBank ${ }^{\mathrm{TM}}$ database. When B1, SAG1, SAG4 and MAG1 oligonucleotide sequences were compared with other sequences, statistically significant E-values were found $(0.003$ and 0.009 for B1 and SAG1, respectively; 0.009 and 0.003 for SAG4 and MAG1 genes, respectively).

No positive reactions in n-PCR assays occurred in control studies with DNA extracted from HIV-negative and immunocompetent patients.

\section{Discussion}

In immunocompromised hosts and in AIDS patients, the reactivation of $\mathrm{TE}$ culminates in the conversion of the bradyzoite stage to the active and rapidly replicating tachyzoite form that results in the often fatal tissue injury associated with TE. These two stages have been shown previously to be antigenically distinct $[1,27]$ However, diagnosis based on serological documentation of stage conversion in human tissue is difficult to interpret and the evidence of previous $\operatorname{IgG}$ seropositivity for $T$. gondii has a limited role in AIDS patients with TE.

Several biological fluids have been tested by PCR based on amplification of different $T$. gondii gene targets such as the $\mathrm{B} 1, \mathrm{P} 30, \mathrm{TGR} 1_{\mathrm{A}} \mathrm{TGR} 1_{\mathrm{E}} \mathrm{TGR} 2$, TGR4, repetitive regions and ribosomal DNA genes [4-6, 10, 29-33]. Converging lines of evidence suggest that PCR sensitivity depends on the sets of primers used and the time elapsing between the start of specific therapy and CSF collection [4, 29, 33, 34]. 
Table 3. Characteristics of TE patients and PCR results in CSF specimens

\begin{tabular}{|c|c|c|c|c|c|c|c|c|c|c|c|c|}
\hline \multirow[b]{2}{*}{ Patient no. } & \multirow[b]{2}{*}{$\begin{array}{l}\text { Sex, age } \\
\text { (years) }\end{array}$} & \multirow[b]{2}{*}{$\begin{array}{l}\mathrm{CD} 4^{+} \text {count } \\
\quad(\text { cells } / \mu 1\end{array}$} & \multirow[b]{2}{*}{$\begin{array}{l}\text { Serum } T \text {. gondii } \\
\mathrm{IgG}\end{array}$} & \multirow[b]{2}{*}{ TE episode } & \multirow{2}{*}{$\begin{array}{l}\text { Anti- } \\
T \text {. gondii } \\
\text { prophylaxis }\end{array}$} & \multirow[b]{2}{*}{$\begin{array}{l}\text { Anti-T. gondii } \\
\text { treatment }\end{array}$} & \multirow[b]{2}{*}{$\begin{array}{l}\text { Response to treatment } \\
\text { or clinical outcome }\end{array}$} & \multirow{2}{*}{$\begin{array}{l}\text { Duration of } \\
\text { therapy before } \\
\text { PCR-CSF } \\
\text { (days) }\end{array}$} & \multicolumn{4}{|c|}{$\begin{array}{l}\text { Results of CSF n-PCR for stage specific } \\
\text { genes }\end{array}$} \\
\hline & & & & & & & & & $B 1$ & $S A G 1$ & SAG4 & $M A G 1$ \\
\hline 1 & $\mathrm{M}, 24$ & 86 & Positive & 1st episode & Yes & $\mathrm{PYR}+\mathrm{SDZ}$ & Improved* & 0 & - & - & - & - \\
\hline 2 & M,29 & 91 & Positive & Relapse & Yes" & $?$ & Died & 1 & NP & - & + & + \\
\hline 3 & $\mathrm{~F}, 31$ & 71 & Positive & Relapse & Yes ${ }^{\star}$ & CTX & Improved, then died* & 1 & + & + & + & + \\
\hline 4 & M,29 & 65 & Negative & 1 st episode & Yes $^{\dagger}$ & PYR+CLIN & Improved & 0.5 & + & - & + & + \\
\hline 5 & M,29 & 108 & Positive & Relapse & Yes" & PYR+AZTR\# & Improved, then died* & $>7$ & - & + & + & + \\
\hline 6 & $\mathrm{M}, 31$ & 11 & Positive & 1 st episode & n.a. & PYR+SDZ & No changes* & $>7$ & - & - & NP & NP \\
\hline 7 & M,29 & 22 & Positive & Relapse & Yes & PYR+SDZ\# & No changes & 0 & - & + & - & + \\
\hline 8 & $\mathrm{~F}, 25$ & 26 & NP & 1 st episode & Yes & PYR+CLIN & Improved* & $>7$ & - & + & + & + \\
\hline 9 & M,32 & 28 & Negative & 1 st episode & n.a. & PYR+SDZ & Improved & $>7$ & + & - & - & - \\
\hline 10 & M,35 & 10 & Negative & 1 st episode & n.a. & $\mathrm{PYR}+\mathrm{SDZ}$ & Improved & 0 & + & - & - & - \\
\hline 11 & M,35 & 43 & Negative & Relapse & Yes" & $\mathrm{PYR}+\mathrm{SDZ}$ & Improved* & 0 & + & - & + & + \\
\hline 12 & M,35 & 5 & Negative & 1st episode & Yes $^{\dagger}$ & $\mathrm{PYR}+\mathrm{SDZ}$ & Improved & 0 & + & - & - & - \\
\hline 13 & M,46 & 13 & $\mathrm{NP}$ & 1st episode & Yes & $\mathrm{PYR}+\mathrm{SDZ}$ & Improved & $>7$ & - & - & + & + \\
\hline 14 & $\mathrm{M}, 41$ & 21 & Positive & Relapse & Yes $^{\dagger}$ & NPף & No changes & 1 & + & + & - & + \\
\hline 15 & $\mathrm{M}, 41$ & 21 & Positive & Relapse & Yes $^{\dagger}$ & NPף & No changes & 1 & + & - & + & + \\
\hline 16 & $\mathrm{~F}, 39$ & 33 & Positive & 1st episode & Yes & PYR+CLIN & Improved & 0 & + & - & - & - \\
\hline 17 & $\mathrm{~J}, 38$ & 31 & Positive & Relapse & Yes: & PYR+SDZ\# & No changes & 0 & + & + & - & + \\
\hline 18 & M,39 & 16 & Positive & Relapse & Yes" & $\mathrm{PYR}+\mathrm{SDZ}^{\S}$ & No changes & 0 & - & + & + & + \\
\hline 19 & M,37 & 25 & Positive & 1 st episode & n.a. & PYR+CLIN & Improved & 0 & + & - & NP & NP \\
\hline 20 & M,29 & 18 & Positive & 1 st episode & Yes & PYR+SDZ & Improved & 0.5 & + & + & + & + \\
\hline 21 & M,28 & 11 & NP & 1 st episode & Yes $^{\dagger}$ & $\mathrm{PYR}+\mathrm{AZR}$ & No changes & 0 & + & - & - & - \\
\hline 22 & $\mathrm{~F}, 28$ & 10 & Positive & 1 st episode & n.a. & CTX & Improved & 0 & + & - & - & - \\
\hline 23 & $\mathrm{~F}, 29$ & 41 & Positive & 1st episode & n.a. & CTX & Improved & 0 & + & + & - & - \\
\hline 24 & $\mathrm{~F}, 33$ & 26 & Negative & 1st episode & n.a. & ATVQ & Improved & 0 & + & - & - & - \\
\hline 25 & $\mathrm{M}, 30$ & 75 & $\mathrm{NP}$ & 1st episode & Yes & ATVQ & Died & 0 & + & - & - & - \\
\hline 26 & M,25 & 50 & Positive & Relapse & Yes: & $\mathrm{PYR}+\mathrm{SDZ}$ & Died & 0 & - & - & + & + \\
\hline 27 & M,25 & 50 & Positive & Relapse & Yes" & PYR+SDZ\# & Died & 0 & - & - & + & + \\
\hline
\end{tabular}

M, male; F, female; +, positive; -, negative; n.a., not available;

PYR, pyrimethamine; SDZ, sulphadiazine; CLIN, clindamycin; AZTR, azithromycin; CTX, co-trimoxazole; NP, not performed.

TE proven at autopsy.

Prophylaxis taken discountinuously.

${ }^{\ddagger}$ Maintenance anti-T. gondii prophylaxis.

${ }^{\S}$ Receiving full doses of therapy.

\#Maintenance therapy.

Not receiving treatment.

?, information missing due to the lack of patient's medical record. 
Table 4. CSF findings obtained by $T$. gondii $\mathrm{n}-\mathrm{PCR}$ in AIDS patients with TE and other related brain lesions (OBL)

\begin{tabular}{|c|c|c|c|c|c|c|}
\hline \multirow{2}{*}{$\begin{array}{l}\text { Study } \\
\text { group }\end{array}$} & & \multirow{2}{*}{$\begin{array}{c}\text { Number of } \\
\text { samples }\end{array}$} & \multicolumn{4}{|c|}{ Number (\%) of samples positive by $n-P C R$ for } \\
\hline & & & B1 & SAG1 & SAG4 & MAG1 \\
\hline \multirow[t]{2}{*}{ Group 1} & TE first episode & 16 & $12(75)^{*}$ & $3(18.7)$ & $4(25)^{\dagger}$ & $4(25)^{\dagger}$ \\
\hline & TE relapse & 11 & $4(36.3)^{*}$ & $5(45.4)$ & $8(72.7)^{\dagger}$ & $8(72.7)^{\dagger}$ \\
\hline Group 2 & AIDS-OBL & 19 & $1(5.2)$ & $0(-)$ & $1(5.2)$ & $1(5.2)$ \\
\hline
\end{tabular}

PCR assays targeting the multi-copy B1 gene of $T$. gondii are the most widely performed tests in molecular diagnosis of toxoplasmosis, as B1 appears to be conserved in different parasite strains and it is present as 25-50 copies/genome [4]. However, PCR assays that amplify the B1 gene or other highly conserved genes, such as P30 and ribosomal genes do not discriminate between DNA of tachyzoites and that released from cyst-derived bradyzoites.

Recent advances in the genetic manipulation of $T$. gondii have expanded the armamentarium of molecular tools that can be applied to studies on bradyzoite differentiation. Although the phenomenon of reactivation is far from being synchronous, as experimentally demonstrated by the simultaneous existence of all forms of $T$. gondii in the brain tissue [13, 18], during immunosuppression in vivo the mechanisms that regulate conversion into bradyzoites are predominant and more bradyzoite surface molecules are expressed [35]. Several bradyzoite genes encoding for specific antigens have been identified and cloned including SAG4, BAG1/hsp30, LDH2 and MAG1 [7, 12, 20, 22]. The cloning and characterisation of these stagespecifically expressed genes has further contributed to the molecular analysis of this developmental differentiation $[3,36,37]$.

Therefore, in this study, different specific primers were used to amplify DNA sequences of $T$. gondii stagespecific genes at bradyzoite and tachyzoite stages. Considering that not all cases of recrudescence are detected by traditionally used CSF PCR assays, the B1 gene, together with other genes such as SAG1, SAG4 and MAG-1, were used as targets. In contrast with previous findings, CSF-PCR with B1 gene proved to be helpful in the diagnosis of acute toxoplasmosis in patients with a first episode of TE $[17,38]$. Furthermore, our data confirmed that a high diagnostic accuracy was achieved when lumbar puncture was performed before or soon after the initiation of antitoxoplasma therapy, whereas the diagnostic sensitivity failed if lumbar puncture was delayed [29]. In agreement with others, no DNA was detected with B1 gene n-PCR in TE patients after $\geqslant 1$ week of antitoxoplasma therapy $[8,9,34,39,40]$. Furthermore, no amplification signal was seen in most of the patients with relapses who were receiving long-term maintenance prophylaxis [38-40]. This indicates that the B1 gene has limited value in monitoring the effects of therapy or prophylaxis.

The B1 gene is repeated 35 times in the $T$. gondii genome, thus being an adequate target for detection by PCR in clinical specimens. In most of the CSF samples, the sensitivities of n-PCR were between $40 \%$ and $50 \%$ with specificities usually nearly $100 \%$ $[9,17,21,22,38]$. The fact that B1 gene n-PCR does not show reproducible usefulness in monitoring therapy may be a result of several factors including the lack of standardised reagents and protocols for DNA extraction, the amplification of DNA fragments of different size or inadequate storage of the CSF, which often affect PCR reproducibility and make comparison of results difficult. Considering that most patients on prophylaxis may undergo TE reactivation, PCR targeting B1 may be less effective in detecting DNA released from cysts. Finally, results obtained by PCR may be affected also by concomitant therapies for other infections such as Pneumocystis carinii or Mycobacterium avium which enhance the anti-toxoplasma activity.

With amplification of the SAG1 gene, the rate of parasite DNA detected in patients with first episodes of TE was lower than that obtained with the n-PCR for the B1 gene. This confirms the greater sensitivity of the B1 system, probably because the former is a repetitive gene and, therefore, is likely to result in a greater production of genomic material. In contrast, SAG1 gene-specific primers detected more relapse cases (45.4\%) than first episodes (28.7\%), although the difference was not significant. In agreement with invitro and in-vivo studies, these findings might suggest that relapsing TE is associated with an increased amount of tachyzoite SAG1 DNA in the CNS associated with rapid parasite replication $[15,35,36]$.

With the exception of three patients (nos 7, 14 and 17) in whom there was discrepancy between amplification of SAG4 and MAG1, the results obtained with oligonucleotide primers directed against these genes were similar. Positive results were found in $72 \%$ of patients with TE relapse and in $25 \%$ of those with first episode of TE. Among the 11 patients with TE relapses, seven (nos 2, 3, 5, 7, 11, 15 and 17) had $T$. gondii DNA in their CSF detectable by these primers, in contrast to four (nos 3,11,14, 15) detected by B1PCR. No relapse cases that were B1-positive were also 
positive for two of SAG1, SAG4 or MAG1. Of the seven TE relapses detected by SAG4/MAG1 gene nPCR, five patients (nos 3, 5, 7, 14 and 18) were also detected by the SAG1 gene n-PCR. These results suggest that during new relapses or early tissue cyst formation, bradyzoite- or tachyzoite-specific molecules are likely to be detected by oligonucleotide primers targeting bradyzoite or tachyzoite molecules. On the other hand, two patients with first episodes of TE and on atovaquone treatment (nos 24 and 25) gave negative results in SAG1, SAG4 and MAG1 gene n-PCR. It is possible that atovaquone, which is more directed against metabolically active bradyzoites than tachyzoites, may be responsible for failure of detection of DNA released from cysts with these primers [41].

The detection of larger amounts of bradyzoite-specific genes in patients with TE relapses than in patients with first episodes of TE may be explained in part by the fact that most patients with relapses were treated repeatedly, after the first episode, with chemotherapeutic agents such as pyrimethamine and sulphadiazine, which have been reported to induce bradyzoite antigen expression and enhance cyst production and bradyzoite development $[3,42]$. Moreover, in these patients, the immunosuppression was more evident as documented by $\mathrm{CD}^{+}{ }^{+}$depletion and increased plasma HIV viral load. It could be speculated that the progressive loss of cellular immunosurveillance, in combination with factors that trigger toxoplasma encystation and molecular mechanisms involved in bradyzoite differentiation, may have promoted reactivation of silent brain cyst or cyst rupture that allow parasites to continue to express bradyzoite surface molecules that are detected more readily by bradyzoite-specific primers during relapses than in first episodes. These findings were recently supported by the use of reverse transcriptase PCR assay, which has demonstrated a more consistent copy number of mRNA SAG-4 and MAG-1 gene transcripts in the CSF of patients with TE relapse than in patients with first episodes of TE [23]. The major representation of MAG-1 gene n-PCR, which amplifies a fragment corresponding to a specific antigenic portion (212 bp), has been shown to be indicative of a greater load of bradyzoites or pre-bradyzoite stages during relapse than in first episodes of TE [23].

Taken together, these data strongly suggest that the higher frequency of detection of the bradyzoite-specific genes is a specific marker of TE relapse and does not reflect the natural history of toxoplasmic disease or of silent CNS toxoplasmic cysts.

In general, the simultaneous use of different PCR assays targeting the SAG1, SAG4 or MAG1 genes during TE relapse might be of value to increase $T$. gondii detection rates. A set of these primers could allow the identification of both acute and reactivation episodes of TE, including cases where the B1 PCR is negative and specific treatment or prophylaxis has been started. These findings further support the view that parasite DNA is released from cysts and cyst matrix despite successful response to previous anti-toxoplasmic treatment, and it is not cleared from the CSF as demonstrated previously [33].

The CSF-PCR findings in the present study were generally associated specifically with acute CNS toxoplasmosis. However, with the strict controls and reproducibility requirements used, two patients with AIDS-OBL had positive n-PCR results for B1, SAG4 and MAG1 genes in their CSF: one of them was suffering from CMV encephalitis, the other from cerebral cryptococcosis. The former had rapidly progressive mental status changes and polyradiculitis in the absence of intracranial mass lesions and he had a rapid course from onset to death. Diagnosis was done by demonstration of CMV-DNA by CSF-PCR assay. The second patient had clinical signs of meningitis and two cerebral hypodense non-enhancing lesions and tests for cryptococcal antigen in CSF and serum were positive. These patients had serum anti-T. gondii antibodies and were taking discontinuously primary prophylaxis against toxoplasmosis. For these patients, clinical outcome was difficult to evaluate. Permission for autopsy was not obtained from parents or relatives.

The CSF samples from these patients gave PCR products of identical size but of comparatively lower signal intensity, probably because of lower copy numbers of the T. gondii DNA target. When the PCR was combined with Southern blot hybridisation, these specimens gave negative results, because of the lower sensitivity of the chemiluminescent detection assay and the higher specificity of Southern blotting, compared with n-PCR.

Homology was not shown with CMV or Cr. neoformans or with the other micro-organisms mentioned above. Primer sequences were compared with other sequenced DNA available from current databases and were found to be non-complementary to any other known sequence. In particular, no cross-reactions between $T$. gondii and either CMV or Cr. neoformans DNA have been shown with homologous specific primers. $T$. gondii oligonucleotides did not exhibit significant homologies when aligned with the entire genomic DNA of Cr. neoformans and CMV. Sequencing of all amplified products confirmed the identity of all the genes amplified. The oligonucleotides employed, when compared with other sequences, produced significant alignments in the GenBank database and a statistically significant homology was found only for $T$. gondii. This assured the specificity of the n-PCR. Thus, the n-PCR assay seems to be both sensitive and specific.

We cannot exclude the possibility that the coincident finding of CMV-DNA and cryptococcal antigen with $T$. gondii bradyzoite genes in CSF specimens may indicate a co-infection. Reactivation of $T$. gondii often 
occurs concurrently with active CMV disease in immunocompromised patients [43].

In conclusion, the use of oligonucleotide probes identifying specific genes involved in the bradyzoitetachyzoite interconversion could provide information to help the understanding of the molecular events surrounding this conversion. Furthermore, the ability to identify $T$. gondii DNA in clinical samples from patients with TE relapses despite therapy or prophylaxis might be also helpful in the diagnosis and monitoring of reactivated toxoplasmosis in immunocompromised patients.

This work was supported by a grant from the Italian Ministry of University and Scientific Research (MURST - 40\%, 2001 and 60\%, 2001). We are also grateful to Professor François Peyron of Department de Parasitologie of "University Claude Bernard", Lyon, France, for providing Toxoplasma gondii RH strain and to Fondazione Carife, Ferrara, Italy.

\section{References}

1. Smith JE, McNeil G, Zhang YW, Dutton S, Biswas-Hughes G, Appleford P. Serological recognition of Toxoplasma gondii cyst antigens. In: Gross U (ed) Toxoplasma gondii. (Current Topics in Microbiology and Immunology vol. 219) Berlin, SpringerVerlag. 1996: 67-73.

2. Partanen $\mathrm{P}$, Turunen HJ, Paasivuo RAT, Leinikki PO. Immunoblot analysis of Toxoplasma gondii antigens by human immunogobulins $\mathrm{G}, \mathrm{M}$, and $\mathrm{A}$ antibodies at different stages of infection. $J$ Clin Microbiol 1984; 20: 133-135.

3. Weiss LM, Kim K. The development and biology of bradyzoites of Toxoplasma gondii. Front Biosci 2000; 5: D391-D405.

4. Burg JL, Grover CM, Pouletty P, Boothroyd JC. Direct and sensitive detection of a pathogenic protozoan, Toxoplasma gondii, by polymerase chain reaction. J Clin Microbiol 1989; 27: $1787-1792$

5. Nicoll S, Burns SM, Brettle RP, Leen CSL. A comparison of two methods of gene amplification for the diagnosis of Toxoplasma gondii in AIDS. J Infect 1996; 33: 177-183.

6. Cazenave J, Cheyrou A, Blouin P, Johnson AM, Begueret J. Use of polymerase chain reaction to detect Toxoplasma. J Clin Pathol 1991; 44: 1037.

7. Bohne W, Parmley SF, Young S, Gross U. In: Gross U (ed) Toxoplasma gondii. (Current Topics in Microbiology and Immunology vol. 219) Berlin, Springer-Verlag. 1996: 81-91.

8. Franzen C, Altfeld M, Hegener P et al. Limited value of PCR for detection of Toxoplasma gondii in blood from human immunodeficiency virus-infected patients. J Clin Microbiol 1997; 35: 2639-2641.

9. Novati R, Castagna A, Morsica G et al. Polymerase chain reaction for Toxoplasma gondii DNA in the cerebrospinal fluid of AIDS patients with focal brain lesions. AIDS 1994; 8: 1691-1694.

10. Pelloux H, Dupouy-Camet, J Derouin F, Aboulker J-P, Raffi F and the Bio-Toxo Study Group. A multicentre prospective study for the polymerase chain reaction detection of Toxoplasma gondii DNA in blood samples from 186 AIDS patients with suspected toxoplasmic encephalitis. AIDS 1997; 11: 1888-1890.

11. Verhofstede C, Reniers S, Colebunders R, van Wanzeele F, Plum J. Polymerase chain reaction in the diagnosis of Toxoplasma encephalitis. AIDS 1993; 7: 1539-1541.

12. Bohne W, Gross U, Ferguson DJP, Heeseman J. Cloning and characterisation of a bradyzoite-specifically expressed gene (hsp30/bag 1) of Toxoplasma gondii related to genes encoding small heat-shock proteins of plants. Mol Microbiol 1995; 16: $1221-1230$.

13. Soëte M, Dubremetz JF. Toxoplama gondii: kinetics of stagespecific protein expression during tachyzoite-bradyzoite conversion in vitro. In: Gross U (ed) Toxoplasma gondii. (Current Topics in Microbiology and Immunology, vol 219) Berlin, Springer-Verlag. 1996: 75-80

14. Parmley SF, Yang S, Harth G, Sibley D, Sucharzuk A,
Remington JS. Molecular characterization of a 65-kilodaldon Toxoplasma gondii antigen expressed abundantly in the matrix of tissue cysts. Mol Biochem Parasitol 1994; 66: 283-296.

15. Lane A, Soete M, Dubremetz JF, Smith JE. Toxoplasma gondii: appearance of specific markers during the development of tissue cysts in vitro. Parasitol Res 1996; 82: 340-346.

16. Savva D, Morris JC, Johnson JD, Holliman RE. Polymerase chain reaction for detection of Toxoplasma gondii. J Med Microbiol 1990; 32: 25-31.

17. Schoondermark van de Ven E, Galama J, Kraaijeveld C, van Druten J, Mewissen J, Melchers W. Value of polymerase chain reaction for the detection of Toxoplasma gondii in cerebrospinal fluid from patients with AIDS. Clin Infect Dis 1993; 16: $661-666$.

18. Soëte M, Fortier B, Camus D, Dubremetz JF. Toxoplasma gondii: kinetics of bradyzoite-tachyzoite interconversion in vitro. Exp Parasitol 1994; 76: 259-264.

19. Kwok S, Higushi R. Avoiding false positives with PCR. Nature 1989; 339: 237-238.

20. Contini C, Seraceni S, Cultrera R. Different PCR systems to detect Toxoplasma gondii tachyzoites or bradyzoites in clinical specimens from patients with and without overt disease. J Eukaryot Microbiol 1999; 46: 77S-78S.

21. Khalifa KES, Roth A, Roth B, Arastah KN, Janischichke K. Value of PCR for evaluating occurrence of parasitemia in immunocompromised patients with cerebral and extracerebral toxoplasmosis. J Clin Microbiol 1994; 32: 2813-2819.

22. Odberg-Ferragut C, Soete M, Engels A et al. Molecular cloning of the Toxoplasma gondii sag-4 gene encoding an 18 kDA bradyzoite specific surface protein. Mol Biochem Parasitol 1996; 82: 237-244.

23. Cultrera R, Seraceni S, Contini C. Efficacy of a novel reverse transcriptase-polymerase chain reaction (RT-PCR) for detecting Toxoplasma gondii bradyzoite gene expression in human clinical specimens. Mol Cell Probes 2002; 16: 31-39.

24. Sambrook J, Fritsch EF, Maniatis T. Molecular cloning: a laboratory manual vol. 2. Cold Spring Harbor, NY, Cold Spring Harbor Laboratory Press. 1989: 9.44.

25. Dembo A, Karlin S, Zeitouni O. Limit distribution of maximal non-aligned two-sequence segmental score. Ann Prob 1994; 22 : 2022-2039

26. Karlin S, Altschul SF. Methods for assessing the statistical significance of molecular sequence features by using general scoring schemes. Proc Natl Acad Sci USA 1990; 87: 2264-2268.

27. Lunde MN, Jacobs L. Antigenic differences between endozoites and cystozoites of Toxoplasma gondii. J Parasitol 1983; 69: $806-808$.

28. Weiss LM, La Place D, Tanowitz HB, Wittner M. Identification of Toxoplasma gondii bradyzoite-specific monoclonal antibodies. J Infect Dis 1992; 166: 213-215.

29. Ammassarri A, Murri R, Cingolani A, De Luca A, Antinori A. AIDS-associated cerebral toxoplamosis: an update on diagnosis and treatment. In: Gross U (ed) Toxoplasma gondii. (Current Topics in Microbiology and Immunology vol. 219) Berlin, Springer-Verlag. 1996: 209-222.

30. Cristina N, Liaud M-F, Santoro F, Oury B, Ambrose-Thomas P. A family of repeated DNA sequences in Toxoplasma gondii: cloning, sequence analysis, and use in strain characterization. Exp Parasitol 1991; 73: 73-81.

31. Roth A, Roth B, Hoffken G, Steuber S, Khalifa KI, Janitschke $\mathrm{K}$. Application of polymerase chain reaction in the diagnosis of pulmonary toxoplasmosis in immunocompromised patients. Eur J Clin Microbiol Infect Dis 1992; 11: 1177-1181.

32. Khoury H, Adkins D, Brown R et al. Successful treatment of cerebral toxoplasmosis in a marrow transplant recipient: contribution of a PCR test in diagnosis and early detection. Bone Marrow Transplant 1999; 23: 409-411.

33. Lamoril J, Molina JM, de Gouvello A et al. Detection by PCR of Toxoplasma gondii in blood in the diagnosis of cerebral toxoplasmosis in patients with AIDS. J Clin Pathol 1996; 49: 89-92.

34. Cingolani A, De Luca A, Ammassari A et al. Detection of $T$ gondii-DNA by PCR in AIDS-related toxoplasmic encephalitis. J Eukaryot Microbiol 1996; 43: 118S-119S.

35. Odaert H, Soête M, Fortier B, Camus D, Dubremetz JF. Stage conversion of Toxoplasma gondii in mouse brain during infection and immunodepression. Parasitol Res 1996; 82: $28-31$. 
36. Gross U, Bohne W, Soëte M, Dubremetz JF. Developmental differentiation between tachyzoites and bradyzoites of Toxoplasma gondii. Parasitol Today 1996; 12: 30-33.

37. Gross U, Bohne W, Luder CGK et al. Regulation of developmental differentiation in the protozoan parasite Toxoplasma gondii. J Eukaryot Microbiol 1996; 43: 114S-116S.

38. Eggers C, Gross U, Klinker H, Schalke B, Stellbrink HJ, Kunze K. Limited value of cerebrospinal fluid for direct detection of Toxoplasma gondii in toxoplasmic encephalitis associated with AIDS. J Neurol 1995; 242: 644-649.

39. Dupoy-Camet J, Lavareda de Souza S et al. Detection of Toxoplasma gondii in venous blood from AIDS patients by polymerase chain reaction. J Clin Microbiol 1993; 31: 1866-1869.

40. Foudrinier F, Aubert D, Puygauthier-Tobas D et al. Detection of Toxoplasma gondii in immunodeficient subjects by gene amplification: influence of therapeutics. Scand J Infect Dis 1996; 28: 383-386.

41. Araujo FG, Huskinson J, Remington JS. Remarkable in vitro and in vivo activities of the hydroxynaphthoquinone 566C80 against tachyzoites and tissue cysts of Toxoplasma gondii. Antimicrob Agents Chemother 1991; 35: 293-299.

42. Gross U, Pohl F. Influence of antimicrobial agents on replication and stage conversion of Toxoplasma gondii. In: Gross U (ed) Toxoplasma gondii. (Current Topics in Microbiology and Immunology, vol. 219) Berlin, Springer-Verlag. 1996: 235-245.

43. Pomeroy C, Kline S, Jordan MC, Filice GA. Reactivation of Toxoplasma gondii by cytomegalovirus disease in mice: antimicrobial activity of macrophages. J Infect Dis 1989; 160: $305-311$. 